\title{
A LOW-COST AND HIGH-YIELD PRODUCTION OF MAGNETITE NANORODS WITH HIGH SATURATION MAGNETIZATION
}

\author{
CHENGLIANG HAN ${ }^{a *}, b, J I N J I N M^{c}$, HANZHAO WU ${ }^{a}, Y$ YOWEI ${ }^{a}, K_{U N H O N G ~ H U}{ }^{a}$ \\ ${ }^{a}$ Department of Chemical and Material Engineering, Hefei University, Hefei 230601, P.R. China \\ ${ }^{b}$ Institute of Solid State Physics, Chinese Academy of Sciences, Hefei, 230031,P.R. China \\ cDepartment of Material Science and Engineering, Nanjing University of Aeronautics and Astronautics, 29 Yudao Street, Nanjing 210016,PR China
}

\begin{abstract}
Nanopowders of single-crystalline rod-like magnetite have been synthesized in a glycerol-water system under hydrothermal condition by using the goethite $(\alpha-\mathrm{FeOOH})$ precursor. The influence of different reaction parameters on the morphology and composition of the products have been investigated. The structure, morphology and magnetic properties of the products were characterized by X-ray diffraction (XRD), field emission scanning electron microscope (FESEM), transmission electron microscope (TEM) and superconducting quantum interference device (SQUID). The results show that every as-prepared $\mathrm{Fe}_{3} \mathrm{O}_{4}$ nanorod with diameter ca.70nm grows along the [110] direction which is one of easy magnetic axes of magnetite. The ratio of glycerol to water has a great effect on the purity at given temperature. Magnetic measurements indicated that the specific saturation magnetization $\left(\mathrm{M}_{\mathrm{s}}\right)$ and coercivity values $\left(\mathrm{H}_{c}\right)$ of magnetite nanorods were $90 \mathrm{emu} / \mathrm{g}$ and $172 \mathrm{Oe}$, respectively. An in situ dissolution-reduction-reassembling formation mechanism is recommended for as-synthesized magnetite nanorods.
\end{abstract}

Key words: magnetite nanorod; preparation; goethite; magnetic properties

\section{INTRODUCTION}

Nanostructured magnetite $\left(\mathrm{Fe}_{3} \mathrm{O}_{4}\right)$ is one of the most important magnetic materials and has extensively practical applications. The magnetic properties and applications of magnetite mainly depend on the size and shape of its crystals. For example, the magnetite nanoparticles (NPs) can be used as nanoadsorbents [1-3], cancer diagnostics and treatment[4,5], contrast agents in magnetic resonance imaging (MRI) $[6,7]$ and other aspects[8,9]. And the one-dimensional magnetite (1D) will be important in building blocks for nanodevices $[10,11]$. A most synthetic method for magnetite NPs is usually carried out by the aqueous coprecipitation of $\mathrm{Fe}^{2+}$ and $\mathrm{Fe}^{3+}$ [12]. However, magnetic-field induction [13-15], chemical vapor deposition [16-19] and hard templated synthetic methods [20-22] have also been developed to fabricate 1D magnetites. The above methods for 1D magnetite usually need some special equipments such as high temperature furnaces and magnetic devices which cause a complex and tedious synthesis process. Additionally, the reported 1D nanostructured magnetites usually have lower magnetizations which restrict their applications in nanodevices and magnetic separation. Recently, the socalled polyol reduction synthesized method has been extensively applied to obtain some metal nanoparticles such as Ag [24-26] and Pt-Pd-Ru [27, 28] nanoparticles with various morphologies. However, comparison with some classical polyol reduction agents such as ethylene glycol and propylene glycol, the glycerol $\left(\mathrm{C}_{3} \mathrm{H}_{8} \mathrm{O}_{3}\right)$ is clearly more convenient because of its lower cost and nontoxicity. Here, a low-cost glycerol reduction method for preparation of the single-crystal magnetite nanorods was presented. The physical and chemical characterization of the synthesized $\mathrm{Fe}_{3} \mathrm{O}_{4}$ nanorods was carried out.

\section{EXPERIMENT SECTION}

The rod-like magnetites were prepared as follows. In a typical preparation, firstly, $0.1 \mathrm{~g}$ needle-like goethite $(\alpha-\mathrm{FeOOH})$ nanopowders were added to $100 \mathrm{ml}$ beaker with $60 \mathrm{ml}$ glycerol-water solution $\left(\mathrm{C}_{3} \mathrm{H}_{8} \mathrm{O}_{3}: \mathrm{H}_{2} \mathrm{O}=3: 2\right)$ and continuously stirred for 20mins to form yellow suspension. then, the above suspended mixed solution was transferred into to a $100 \mathrm{~mL}$ Teflon-lined autoclave and maintained at $180^{\circ} \mathrm{C}$ for $24 \mathrm{~h}$. After cooling to ambient temperature naturally, the solid black magnetic products in the autoclave were collected by a magnet and ultrasonically rinsed for several times with deionized water and ethanol, respectively. Finally, the products were dried in a vacuum oven at $100^{\circ} \mathrm{C}$ for $6 \mathrm{~h}$.

X-ray diffraction (XRD) patterns were conducted on a Philips X'pert diffractometer using CuK radiation $(0.15419 \mathrm{~nm})$. Morphology and structure of the products were analyzed on a Sirion 200 FEG field emission scanning electron microscope (FESEM) and a JEOL-2010 high resolution transmission electron microscope (Oxford, Link ISIS, and HRTEM), respectively. Magnetization measurements were carried out on a superconducting quantum interference device (SQUID) at room temperature.

\section{RESULTS AND DISCUSSION}

\subsection{Morphology and Structure}

After the precursor solution was heated at $180^{\circ} \mathrm{C}$ for $24 \mathrm{~h}$, the black powders were collected by a magnet. The corresponding XRD is illustrated in Figure.1. The diffraction peaks match well with the standard pattern of $\mathrm{Fe}_{3} \mathrm{O}_{4}$ (JCPDS NO.89-4319) which indicates that the as-prepared product is $\mathrm{Fe}_{3} \mathrm{O}_{4}$ phase.

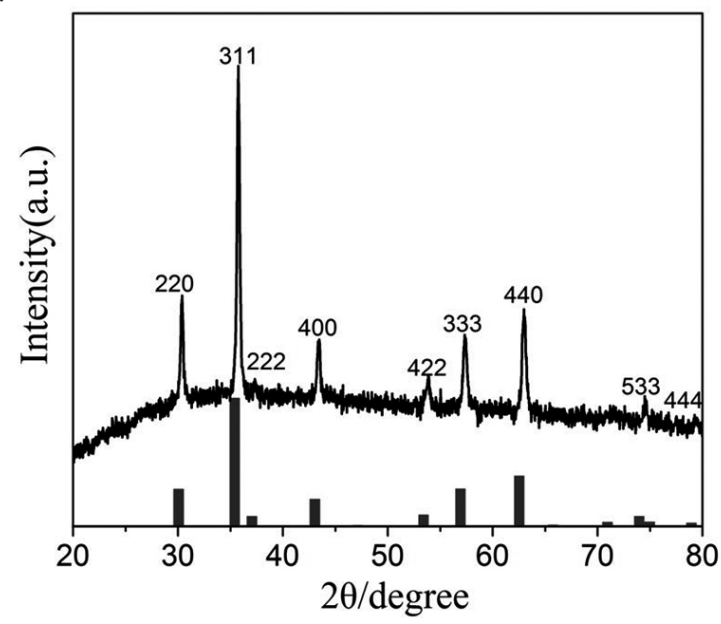

Figure 1. XRD patterns of the as-synthesized product and standard $\mathrm{Fe}_{3} \mathrm{O}_{4}$ powders

Field emission scanning electron microscopic (FESEM) observations have shown that the as-obtained $\mathrm{Fe}_{3} \mathrm{O}_{4}$ is of rod-like morphology with a nearly rectangular shape, as illustrated in Figure 2a. Every rod is several micrometers in length and ca.70nm in diameter (see Fig. 2b).

TEM images of as-prepared magnetite nanorods are demonstrated Figure 3. The select-area electron diffraction (SAED) pattern (the inset of Fig.3a) obtained along a typical individual magnetite nanorod, which demonstrated that the nanorods are single crystals. Moreover, the high-resolution transmission electron microscopy (HRTEM) image of the boxed area in Figure 3a further supported the single-crystalline nature of these magnetite nanorods (Fig.3b). The lattice fringes $(\sim 0.29 \mathrm{~nm})$ observed in this image agree well with the separation between the (220) lattice planes which indicate that the as-prepared magnetite nanorods grow along [110] direction which is in good agreement with the reported literature $[17,19]$. 

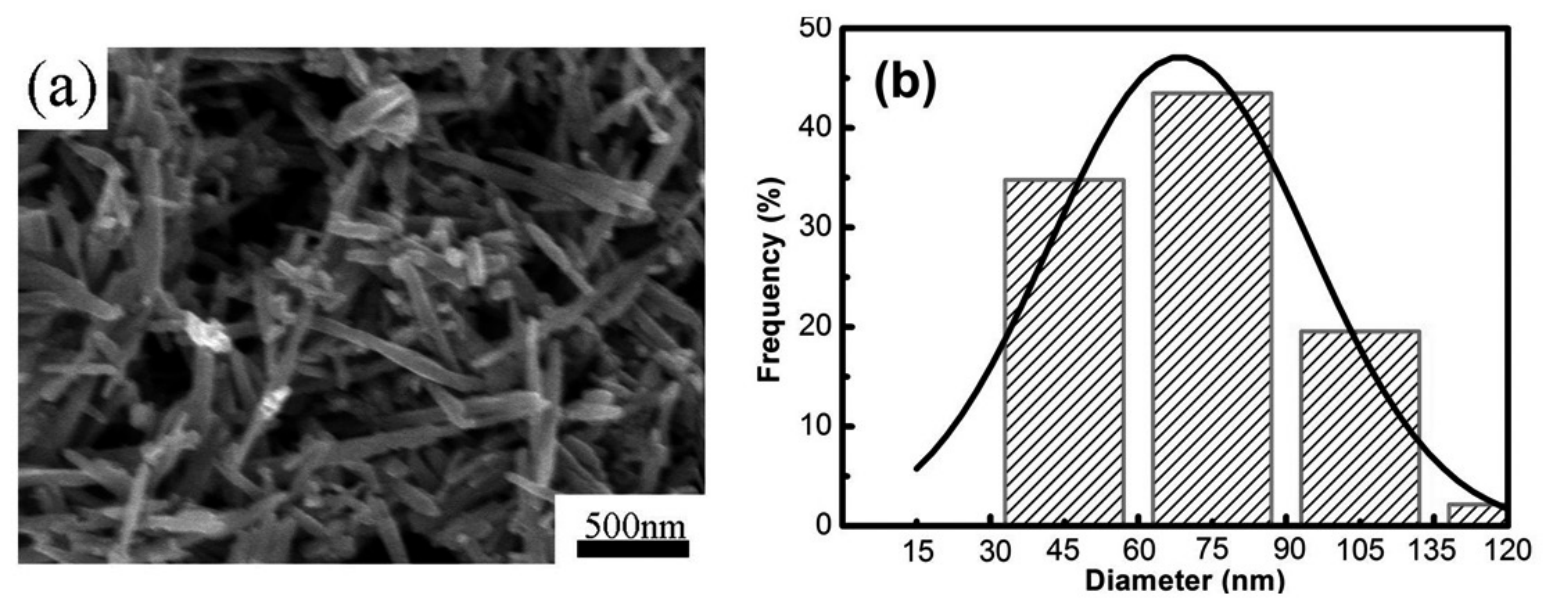

Figure 2. Morphology and size distribution of the as-prepared sample. (a)FESEM image. (b)Diameter distribution of the magnetite nanorods obtained from Figure 2(a), solid-line: Gaussian-type fitting curve.
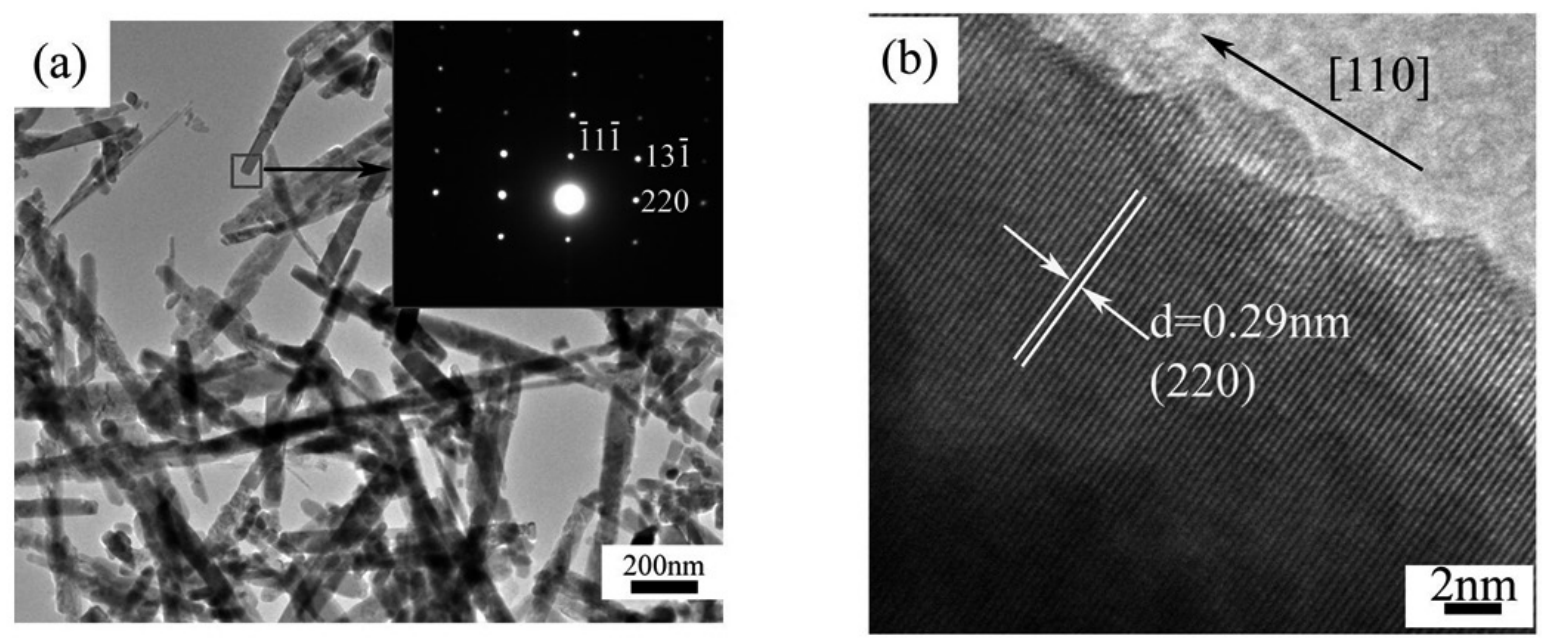

Figure 3. TEM image of a typical $\mathrm{Fe}_{3} \mathrm{O}_{4}$ nanorod (a); the inset in (a) shows an SAED pattern of the individual $\mathrm{Fe}_{3} \mathrm{O}_{4}$ nanorod.(b) HRETM image of the nanorods boxed area in (a).

3.3 Formation of rod-like magnetite

Deep and systematic studies have revealed that several factors such as the precursor, kinds of reducing agents and ratio of glycerol to water are crucial to formation of the magnetite. Firstly, the reaction temperature determines the chemical reaction rate and hence plays an important role in the formation of $\mathrm{Fe}_{3} \mathrm{O}$. It has been found that no reaction took place if the temperature was below $180^{\circ} \mathrm{C}$, and too high temperature was power-wasting and not beneficial to the formation of $\mathrm{Fe}_{3} \mathrm{O}_{4}$. Secondly, it was found that the ratio of $\mathrm{C}_{3} \mathrm{H}_{8} \mathrm{O}_{3}$ to $\mathrm{H}_{2} \mathrm{O}$ had a great effect on the composition of the products. The relative experimental results have been shown in the Figure 4.

From the results in Fig.4, it was found that the pure hematite $\left(\alpha-\mathrm{Fe}_{2} \mathrm{O}_{3}\right)$ will be achieved in a pure water reaction system. As the volume ratio of $\mathrm{C}_{3} \mathrm{H}_{8} \mathrm{O}_{3}$ increases, the yield of magnetites increases. The pure magnetites will be successfully obtained when the ratio of glycerol to water is $6: 4$. However, no magnetite will be gained in a pure glycerol system. Therefore, magnetites can not be acquired in pure water and glycerol reaction systems. Additionally, $\mathrm{Fe}_{3} \mathrm{O}_{4}$ nanoparticles will be acquired by using amorphous $\mathrm{Fe}(\mathrm{OH})_{3}$ precursor instead of needle-like $\alpha-\mathrm{FeOOH}$ at the same experimental condition (seen from Fig.5a). Therefore, the precursor has influence on the morphology of asprepared magnetite.

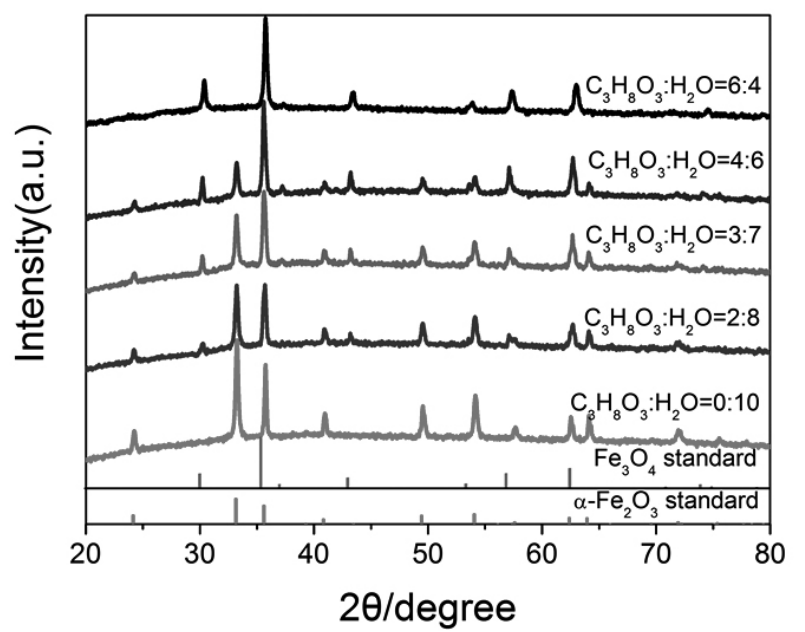

Figure 4. XRD patterns of the products obtained from different ratios of glycerol to water. 

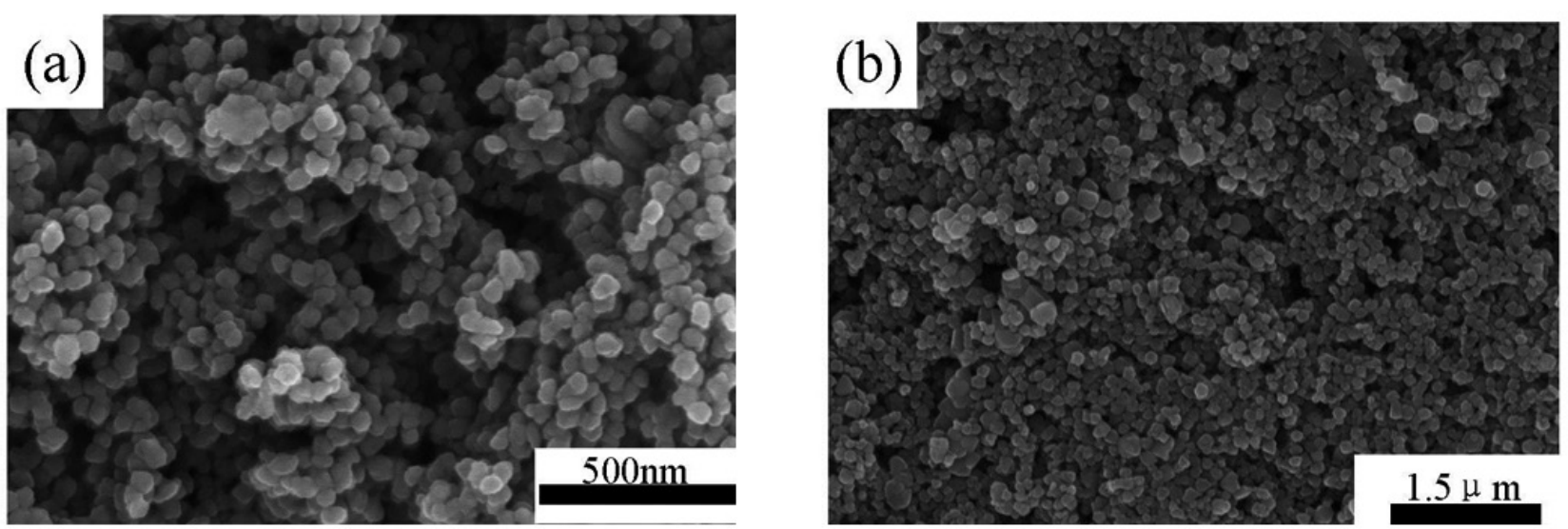

Figure 5. SEM images of the magnetite obtained from $\mathrm{Fe}(\mathrm{OH})_{3}$ precursor (a) and ethylene glycol reducing agents (b).

Finally, if the other reducing agents such as ethylene glycol (EG) are used instead of glycerol, $\mathrm{Fe}_{3} \mathrm{O}_{4}$ nanoparticles will also be obtained from the needleshaped $\alpha$-FeOOH precursor(seem from Fig. $5 b$ ). It is convinced that the shape of precursor and the kind of reducing agents play vital roles in controlling the morphology of magnetite at the same given reaction system.

Based on the above experimental results and discussion, the formation progress of rod-like magnetite in the $\mathrm{C}_{3} \mathrm{H}_{8} \mathrm{O}_{3}-\mathrm{H}_{2} \mathrm{O}$ reaction system was as follows.

$$
\begin{aligned}
& \alpha-\mathrm{FeOOH}+\mathrm{H}_{2} \mathrm{O} \stackrel{180^{\circ} \mathrm{C}}{\longrightarrow} \mathrm{Fe}(\mathrm{OH})_{3} \\
& \mathrm{Fe}(\mathrm{OH})_{3}+\mathrm{C}_{3} \mathrm{H}_{8} \mathrm{O}_{3} \stackrel{180^{\circ} \mathrm{C}}{\longrightarrow} \mathrm{Fe}(\mathrm{OH})_{2}+\mathrm{C}_{3} \mathrm{H}_{7} \mathrm{O}_{3}+\mathrm{H}_{2} \mathrm{O} \\
& 6 \mathrm{Fe}(\mathrm{OH})_{2}+\mathrm{O}_{2} \stackrel{180^{\circ} \mathrm{C}}{\longrightarrow} 2 \mathrm{Fe}_{3} \mathrm{O}_{4}+6 \mathrm{H}_{2} \mathrm{O} \\
& \mathrm{nC}_{3} \mathrm{H}_{7} \mathrm{O}_{3} \stackrel{180^{\circ} \mathrm{C}}{\longrightarrow} \mathrm{HO}-\left(\mathrm{CH}_{2} \mathrm{CHOCH}_{2}-\mathrm{O}-\right)_{\mathrm{n}}+\mathrm{nH}_{2} \mathrm{O}
\end{aligned}
$$

During heating at $180^{\circ} \mathrm{C}$, first of all, the needle-like $\alpha$-FeOOH precursor will gradually dissolve in situ to form $\mathrm{Fe}(\mathrm{OH})_{3}$ [reactions(1)] which is subsequently reduced into $\mathrm{Fe}(\mathrm{OH})_{2}$ by $\mathrm{C}_{3} \mathrm{H}_{8} \mathrm{O}_{3}$ [reaction(2)]. Then, the $\mathrm{Fe}(\mathrm{OH})_{2}$ will be immediately oxidized into $\mathrm{Fe}_{3} \mathrm{O}_{4}$ molecules [reactions (3)]. When the concentration of $\mathrm{Fe}_{3} \mathrm{O}_{4}$ molecules was supersaturated, ultrafined $\mathrm{Fe}_{3} \mathrm{O}_{4}$ nanoparticles will be formed in the solution by nucleation and growth. In order to reduce the energy of the reaction system, these ultrafined $\mathrm{Fe}_{3} \mathrm{O}_{4}$ nanoparticles will be assembled into $\mathrm{Fe}_{3} \mathrm{O}_{4}$ crystal nanorods under the chain-like polyglycerol molecule templates which are generated from the glyceraldehydes at $180^{\circ} \mathrm{C}$ [reactions (4)]. From the above discussion, it was convinced that the shape of precursor, the kind of reducing agents and the ratio of $\mathrm{C}_{3} \mathrm{H}_{8} \mathrm{O}_{3}$ to $\mathrm{H}_{2} \mathrm{O}$ play vital roles in the formation of rod-like magnetite. Therefore, a dissolution-reductiontemplate assembling formation mechanism of $\mathrm{Fe}_{3} \mathrm{O}_{4}$ nanorods can be took into consideration.

\subsection{Magnetic properties}

Fig. 6 shows magnetization hysteresis loop of the as-obtained rod-like magnetite which exhibits a typical ferromagnetic behavior. The oriented singlecrystal rod-like magnetites have excellent magnetic properties. The saturation magnetization of $\left(\mathrm{M}_{\mathrm{s}}\right)$ and the coercivity $\left(\mathrm{H}_{\mathrm{c}}\right)$ are about $90 \mathrm{emug}^{-1}$ and $172 \mathrm{Oe}$ as shown in the down-right inset of Fig.6, corresponding to an expanded low-field hysteresis curve, which are close to the values of bulk $\mathrm{Fe}_{3} \mathrm{O}_{4}\left(85-100 \mathrm{emug}^{-1}\right.$ and 115-150Oe, respectively) $[16,29]$. The high $\mathrm{H}$ and $\mathrm{M}$ of rod-like magnetites can be attributed to the magnetic anisotropy of as-prepared $\mathrm{Fe}_{3} \mathrm{O}_{4}$ crystals which are fast separated in 10 secs by placing a magnet near the vessels (seen from the up-right inset of Fig.6) .Therefore, the as-prepared $\mathrm{Fe}_{3} \mathrm{O}_{4}$ nanorods are promising to be applied in constructing nanoscale magnetic devices and high-density storage media.



Figure 6. Magnetization curves of the magnetite nanorods at 300K. The up-right inset shows the magnetic nanorods respond to an external magnet and the down-right inset is an expanded low-field curve.

\section{CONCLUSION}

In summary, we developed a convenient and low-cost route to highyield single-crystal $\mathrm{Fe}_{3} \mathrm{O}_{4}$ nanorods. It was found that the precursors, the kind of reducing agents and the ratio of glycerol to water were all the crucial factors that determined the composition and morphologies of the products. More importantly, the as-prepared $\mathrm{Fe}_{3} \mathrm{O}_{4}$ nanorods had a magnetic saturation value as high as $90 \mathrm{emu}^{-1} \mathrm{~g}^{-1}$ and hoped to be applied in fabricating magnetic nanodevices and high-density storage media. Furthermore, some other oxide hydroxides such as $\beta-\mathrm{FeOOH}$ and $\gamma-\mathrm{FeOOH}$ can also be used for obtaining one-dimensional $\mathrm{Fe}_{3} \mathrm{O}_{4}$ nanostructures using this synthesized method. The related researches should be also valued in the future.

\section{ACKNOWLEDGEMENT}

The authors wish to acknowledge with thanks support of this research by the National Natural Science Foundation of China (Grant No. 51375139) and Natural Science Foundation of Hefei University (Grant No. 13RC09).

\section{REFERENCES}

1.- Giuliana Magnacca, Alex Allera, Enzo Montoneri, Luisella Celi, Damián E. Benito, Leonardo G. Gagliardi, Mónica C. Gonzalez, Daniel O. Mártire and Luciano Carlos. ACS Sustainable Chem. Eng. 2, 1518 (2014).

2.- Cafer T. Yavuz, J. T. Mayo, William W. Yu, Arjun Prakash, Joshua C. Falkner, Sujin Yean, Lili Cong, Heather J. Shipley, Amy Kan, Mason Tomson, Douglas Natelson, Vicki L. Colvin, Science, 314, 964 (2006).

3.- Hea Thera, Wiatrowski, Soumyadas, Ravikuk Kadapu, Eugenes, Ilton, Tamarbarkay, and Nathanyee, Environ. Sci. Technol. 43, 5307 (2009). 
4.- Young-wook Jun, Yong-Min Huh, Jin-sil Choi, Jae-Hyun Lee, Ho-Taek Song, Sungjun Kim, Sarah Yoon, Kyung-Sup Kim, Jeon-Soo Shin, JinSuck Suh, and Jinwoo Cheon, J. Am. Chem. Soc. 127, 5732 (2005).

5.- Fengqin Hu, Li Wei, Zhuan Zhou, Yuliang Ran, Zhen Li, and Mingyuan Gao, Adv. Mater. 18, 2553 (2006).

6.- Li Yao, Shoujun Xu, Long-Range, Angew. Chem. Int. Ed. 48, 1 (2009).

7.- Jung-tak Jang, Hyunsoo Nah, Jae-Hyun Lee, Seung Ho Moon, Min Gyu Kim, and Jinwoo Cheon, Angew. Chem. Int. Ed. 48, 1234 (2009).

8.- Sascha Ceylan, Carsten Friese, Christian Lammel, Karel Mazac, and Andreas Kirschning, Angew. Chem. Int. Ed. 47, 8950 (2008).

9.- Peter Kopčanský, Natália Tomašovičová, Martina Koneracká, Vlasta Závišová, Milan Timko, Anežka Džarová, and Adriana Šprincová, Physical Review E . 78,011702 (2008).

10.- Z. L. Wang, J. H. Song, Science, 312, 242(2006).

11.- M. Law, L. E. Greene, J. C. Johnson, R. Saykelly, P. Yang, Nat. Mater. 4, 455(2005).

12.- Jos J. M. Lenders, Cem L. Altan, Paul H. H. Bomans, Atsushi Arakaki, Seyda Bucak, Gijsbertus de With, and Nico A. J. M. Sommerdijk, Cryst. Growth Des. 2, 1518 (2014)

13.- Jun Wang, Qianwang Chen, Chuan Zeng, Binyang Hou, Adv. Mater. 16,137 (2004).

14.- Hui Wang, Qian-Wang Chen,Li-Xia Sun, Hai-ping Qi, Xi Yang, Shuai Zhou, and Jie Xiong, Langmuir, 25, 7135 (2009).

15.- Jianfei Sun, Yu Zhang, Zhongping Chen, Jie Zhou, and Ning Gu, Angew. Chem. Int. Ed. 46, 4767 (2007).
16.- Fei Liu, Peijiang Cao, Huairuo Zhang, Jifa Tian, Congwen Xiao, Chengmin Shen, Jianqi Li, Hongjun Gao, Adv. Mater. 17, 1893 (2005).

17.- Yong Ding, Jenny Ruth Morber, Robert L. Snyder, and Zhong Lin Wang, Adv. Funct. Mater. 17, 1172 (2007).

18.- Dai Hua Zhang,Zuqin Liu,Song Han,Chao Li, Bo Lei, Michael P. Stewart, James M. Tour, and Chongwu Zhou, Nano Lett. 4, 2151 (2004).

19.- Sanjay Mathur, Sven Barth, Ulf Werner, Francisco Hernandez-Ramirez, and Albert Romano-Rodriguez, Adv. Mater. 20, 1550 (2008).

20.- Timothy A. Crowley, Kirk J. Ziegler, Daniel M.Lyons,Donats Erts,Håkan Olin, Michael A. Morris, and Justin D. Holmes, Chem. Mater. 15, 3518 (2003).

21.- Hong-Wen Wang, Hsiu-Chu Lin, and Yun-Chieh Yeh, Int. J. Appl. Ceram. Technol. 7, 33 (2010).

22.- Zu Qin Liu, Daihua Zhang, Song Han, Chao Li, Bo Lei, Weigang Lu, Jiye Fang, and Chongwu Zhou, J. Am. Chem. Soc. 127,6(2005).

23.- Carroll, K.J., Reveles, J.U., Shultz, M.D., Khanna, S.N., Carpenter, E.E. J. Phys. Chem. C. 115, 2656 (2011).

24.- Rele, M., Kapoor, S., Sharma, G.; Mukherjee, T. Phys. Chem. Chem. Phys. 6,590(2004).

25.- Ullah, M.H., Kim, I., Ha, C.-S. Mater. Lett. 60, 1496(2006).

26.- Kou, J.; Varma, R.S. Chem. Commun. 49,692(2013).

27.- Grace, A.N., Pandian, K. Mat. Chem. Phys. 104,191(2007).

28.- Lee, Y.-W., Han, S-B., Ko, A.R.; Kim, H-S., Park, K.-W. Catal. Commun. 15,137(2011)

29.- Chun-Jiang Jia, Ling-Dong Sun, Feng Luo al. J. Am. Chem. Soc. 130, 16968(2008). 